\title{
Dificultades de la adopción de niños en Colombia a partir de la jurisprudencia de la Corte Constitucional entre 2011 y $2016^{1}$
}

\author{
Difficulties in adoption of children in Colombia, a look from the jurisprudence of the \\ Constitutional Court between 2011 and 2016
}

Recibido: 07 de diciembre de 2016 - Revisado: 29 de septiembre de 2017 - Aceptado: 22 de noviembre de 2017.

Lina Marcela Estrada Jaramillo

Beatriz María Arango Orozco ${ }^{3}$

Daniela Carrasquilla Zuluaga ${ }^{4}$

Ángela María Mesa González, Carolina Vergara Tobón,

Manuela Noreña González, Manuela Tamayo Monsalve,

Daniela López Lopera, Julián Andrés Correa Barros ${ }^{5}$

\section{Resumen}

Este artículo pretende identificar las dificultades administrativas y judiciales en el proceso de adopción en Colombia a partir del análisis de las sentencias de la Corte Constitucional durante los años 2011 al 2016. Se parte de una investigación de tipo socio jurídica, utilizando el método analítico descriptivo basado en el estudio de las sentencias, identificadas desde preguntas orientadas a las dificultades en el proceso de adopción. Esta investigación permitió identificar la adopción como un mecanismo orientado primordialmente a satisfacer el interés superior de los niños cuando la familia no garantiza las condiciones para la realización y ejercicio de sus derechos; y evidenció que aún falta precisión y efectividad a la hora de aplicar la normatividad y los principios señalados en la Convención de los Derechos del Niño.

Palabras clave

Proceso de adopción, institucionalización de niños, restablecimiento de derechos.

\begin{abstract}
This article aims to identify the administrative and judicial difficulties in the adoption process in Colombia, from the analysis of the Constitutional Court's judgments during the years 2011 to 2016. Taking as a basis the socio-legal type research and using an analytical descriptive method based on the study of judgments, defined from questions oriented to the difficulties in the adoption process. This research identified the adoption as a mechanism oriented towards satisfying the best interests of children when the family does not guarantee the conditions for the realization and exercise of their rights. Finally, it showed that there is still a lack of precision and effectiveness in applying the regulations and principles set forth in the Convention on the Rights of the Child.
\end{abstract}

\section{Keywords}

Adoption process, institutionalization of children, restoration of rights.
${ }^{1}$ Este artículo se escribe como avance de la investigación "La adopción de niños en Colombia y sus dificultades en la práctica administrativa y judicial" de la Universidad Pontificia Bolivariana. La investigación es financiada por el Centro de Investigación para el Desarrollo y la Innovación-CIDI.

${ }^{2}$ Abogada de la Universidad de San Buenaventura. Especialista en Derecho de Familia de la Universidad Pontificia Bolivariana, Magíster en Derecho de la Universidad de Antioquia. Docente de la Universidad Pontificia Bolivariana Medellín, Colombia.

Correo electrónico:

lina.estrada@upb.edu.co [6] https://orcid.org/0000-0002-81627272

3 Abogada, Universidad Pontificia Bolivariana. Especialista en Derecho Comercial, Laboral y Civil. Directora del Centro de Conciliación y Arbitraje "Darío Velásquez Gaviria". Coinvestigadora.

Correo electrónico:

beatrizmaria.arango@upb.edu.co

${ }^{4}$ Abogada de la Facultad Derecho de la Universidad Pontificia Bolivariana. Conciliadora en Derecho.

Correo electrónico:

danielacarrasquilla7@gmail.com

${ }^{5}$ Estudiantes de la Facultad de Derecho de la Universidad Pontificia Bolivariana.

Para citar este artículo use: Estrada, L., Arango, B., Carrasquilla, D. Mesa, A., Vergara, C., Noreña, M., Tamayo, M., López, D., y Correa, J. (2018). Dificultades de la adopción de niños en Colombia a partir de la jurisprudencia de la corte constitucional entre 2011 y 2016. Civilizar, 18(35), 1-12. doi:10.22518/ usergioa/jour/ccsh/2018.2/a01 


\section{Introducción}

Tras la expedición de la Constitución Política de 1991, la legislación sobre familia en Colombia presentó un cambio importante en términos de garantizar el derecho a la igualdad, especialmente en lo relativo a derechos de la infancia y de la adolescencia, asunto que la jurisprudencia de la Corte Constitucional ha venido asumiendo y decantando a través de sus precedentes jurisprudenciales. Entre el catálogo de derechos establecidos en la Carta Política se encuentra el derecho a tener una familia y a no ser separado de ella, el cual se ha constituido como derecho fundamental de los niños y se consagra en el Artículo 44. Así, a partir de los preceptos del Estado Social de Derecho, se definió a la familia como la institución básica de la sociedad.

Posteriormente, en el año 2011, a partir de la sentencia T-844 de la Corte Constitucional, el Instituto Colombiano de Bienestar Familiar diseñó un protocolo que obligaba a los Defensores de Familia a buscar la familia extensa, entendiendo por esta, hasta el sexto grado de consanguinidad, lo cual como lo señaló el Consejo de Estado "ha causado un represamiento en materia de adopciones, pues dicha búsqueda dificulta que los menores sean entregados a sus posibles nuevas familias" (Sala de Consulta y Servicio Civil, 2014). La situación descrita ocasionó una reducción de más del $60 \%$ de las adopciones, de acuerdo a las estadísticas del Instituto Colombiano de Bienestar Familiar (Cuartas-Rodríguez, 2015).

Por lo anterior, la investigación tuvo como objetivo principal identificar las dificultades administrativas y judiciales frente al proceso de adopción en Colombia, a partir del análisis de sentencias de la Corte Constitucional durante los años 2011 - 2016. Se quiso realizar el rastreo jurisprudencial toda vez que los procesos de adopción han tenido, en la jurisdicción constitucional, un desarrollo importante y es allí donde se han evidenciado falencias y conflictos cotidianos que superan la normatividad actual.
La investigación desarrollada fue de tipo socio-jurídico. Se utilizó el método analítico para la obtención de los resultados del estudio. Se emplearon como fuentes: bibliografía especializada, normatividad vigente, jurisprudencia nacional que permitieron hacer una evaluación y posterior diagnóstico acerca de la realidad colombiana frente a la larga espera que viven los niños institucionalizados por el Instituto Colombiano de Bienestar Familiar que se encuentran bajo la Resolución de Declaratoria de Adoptabilidad.

Tabla 1.

Niños y Adolescentes dados en adopción entre los años 2010 al 2016

\begin{tabular}{r|r|r|r}
\hline Año & I.C.B.F & $\begin{array}{r}\text { Instituciones } \\
\text { autorizadas }\end{array}$ & Total \\
\hline 2010 & 2.602 & 456 & 3.058 \\
\hline 2011 & 2.295 & 418 & 2.713 \\
\hline 2012 & 1.197 & 268 & 1.465 \\
\hline 2013 & 942 & 183 & 1.125 \\
\hline 2014 & 922 & 226 & 1.148 \\
\hline 2015 & 856 & 226 & 1.082 \\
\hline 2016 & 936 & 245 & 1.181 \\
\hline Total & $\mathbf{9 . 7 5 0}$ & $\mathbf{2 . 0 2 2}$ & $\mathbf{1 1 . 7 7 2}$ \\
\hline
\end{tabular}

Fuente: Dirección de Protección. Subdirección de Adopciones, 2016.

Para el análisis de las sentencias se utilizó la siguiente pregunta orientadora ¿Cuáles son las dificultades que se evidencian en las sentencias de la Corte Constitucional que influyen en el proceso de la adopción de los niños en Colombia?

La técnica empleada para la consecución de la meta propuesta se realizó a través de una ficha de análisis elaborada por el grupo de investigación, la cual contenía las siguientes categorías:

- Referencia (Tipo de Sentencia)

- Fecha de la sentencia

- Hechos 
- Análisis de la adopción como medida de protección

- Problemas administrativos encontrados en el proceso

- Problemas judiciales encontrados en el proceso

- Decisión de la Corte Constitucional

- Sentencias referenciadas como apoyo para la decisión final

A través de la base de datos Lex Base se obtuvieron diez (10) sentencias dentro del rango de los años 2011 - 2016, las cuales fueron analizadas a través del instrumento de recolección de información. Las sentencias halladas fueron las siguientes: C-104 de 2016, T-119 de 2016, T-071 de 2015, C-683 de 2015, T-129 de 2015, T-044 de 2014, T-212 de 2014, T-664 de 2012, T-502 de 2011, T-844 de 2011.

Se determinó realizar el estudio desde el año 2011 porque tanto la doctrina como la jurisprudencia, señalan la sentencia T-844 de 2011 como una "sentencia hito" que determinó el rumbo de las adopciones en Colombia. Igualmente, porque a partir del 2011 ya estaban en vigencia el Código de Infancia y Adolescencia -Ley 1098 de 2006- y el Lineamiento Técnico Administrativo del Programa de Adopción del Instituto Colombiano de Bienestar Familiar, -Resolución 3748 de 2010- el cual describe el programa de adopción en todas sus etapas.

\section{Resultados}

Esta investigación evidenció las dificultades administrativas y judiciales que generaron una disminución en las adopciones en Colombia desde el año 2011. Esto ha traído como consecuencia la institucionalización de niños que tienen en su contra el paso del tiempo, pues cada día implica una espera de familias que han perdido el interés por adoptarlos. En Colombia, estas dificultades se incrementaron a raíz de la sentencia de la Corte Constitucional T-844 de 2011, que dio base a una interpretación por parte del ICBF en el sentido de adelantar la búsqueda de la familia de origen del niño hasta el sexto grado de consanguinidad (Salcedo, 2015).

Como consecuencia de esta búsqueda, se tiene que los niños pertenecientes a grupos de hermanos, en situación de discapacidad y mayores de diez años se consideran con "características o necesidades especiales", y son quienes viven las consecuencias de la institucionalización. Se denominan de esta manera porque requieren un cuidado diferencial que atienda a sus particularidades físicas, emocionales, conductuales, psicológicas y situacionales. Luego de realizar la revisión de las sentencias de la Corte Constitucional frente a las dificultades administrativas y judiciales en la adopción, se presentaron los siguientes hallazgos:

\section{El proceso de adopción}

El trámite de adopción se encuentra dividido en dos etapas, la primera es un trámite administrativo, el cual se surte ante el ICBF o en las Instituciones Autorizadas para Desarrollar Programas de Adopción -IAPAS. La segunda es la etapa judicial, en donde la adopción es decretada por medio de una sentencia judicial, que establece la relación paternofilial entre adoptado y adoptante de forma irrevocable. Para todos los casos, es necesario cumplir con ambas etapas, de lo contrario la adopción no surtirá efectos.

En la etapa administrativa es necesario tener en cuenta que un niño llega por las siguientes circunstancias 1) Fue declarado en adoptabilidad; 2) Sus padres dieron su consentimiento para la adopción; 3) El Defensor de Familia autorizó su adopción, lo cual implica la separación definitiva con su familia biológica y la obligación para el Estado de buscar su familia adoptiva para restablecer su derecho a tener una familia.

En esta etapa los profesionales que participan en la preparación deben tener en cuenta 
la edad del niño, sus posiciones personales, sus expectativas frente al Proceso de Restablecimiento de Derechos y los recursos personales con los que cuenta que le permitan asimilar la Medida de Adopción (Instituto Colombiano de Bienestar Familiar, 2016).

La historia de atención del niño que tiene la medida de adoptabilidad en firme es presentada al Comité de Adopciones y luego se da la aceptación de la asignación por parte de la familia adoptante, ésta tiene un tiempo de integración con el niño el cual es certificado por el Secretario del Comité de Adopciones. Posteriormente con los requisitos legales exigidos en la Ley de Infancia y Adolescencia en los artículos 124 y 125 es llevado un proceso judicial mediante apoderado ante el Juez de Familia que decreta la adopción plena a través de una sentencia judicial.

Debido a la importancia que tiene el proceso de restablecimiento de derechos en la jurisprudencia de la Corte Constitucional, previo al trámite administrativo de la adopción, se encontraron dos problemáticas que impiden la eficacia de ésta medida de protección. El primer obstáculo radica en la amplia discrecionalidad con la que cuentan los Defensores de Familia, a la hora de efectuar la evaluación y seguimiento a los casos que reciben, esto debido a la acumulación excesiva de procesos. El segundo problema se evidencia en la inobservancia a la obligación que consagra el Artículo 12 de la Convención de los Derechos del Niño, que establece el derecho que tienen de ser escuchados en los trámites en los que hagan parte.

\section{Discrecionalidad de los Defensores de Familia en el proceso administrativo de restablecimiento de derechos.}

En el proceso administrativo de restablecimiento de derechos, donde se señala la medida de restablecimiento de derechos, el Defensor de Familia goza de una discrecionalidad para efectos de verificar la situación fáctica del niño. No obstante, esta discrecionalidad no puede significar arbitrariedad y su aplicación debe obedecer a criterios objetivos, máxime cuando uno de los derechos del niño de rango constitucional, es el de tener una familia y no ser separado de ella, estableciéndose una presunción legal a favor de la familia de origen, tal como ha reiterado nuestra Corte Constitucional en las sentencias T-502 de 2011, T-664 de 2012 y T-844 de 2011.

En este sentido, los Defensores de Familia han optado por establecer sus propios criterios para establecer la separación del niño de su familia, determinando dicha separación por cuestiones de pobreza o falta de educación básica de los padres; cuando la obligación estatal reiterada en los tratados internacionales de derechos humanos es la de propender por la unidad de las familias y su correcto desarrollo, entendiendo que la familia es la institución primaria de protección en los derechos de la infancia.

Consecuentes con lo anterior, se evidencia que dicha discrecionalidad es producto, en gran medida de pautas claras; si bien existen los lineamientos técnicos del ICBF para tal fin, estos no se cumplen a cabalidad o representan vacíos para los funcionarios. Ello deriva en que las decisiones que se toman, van en contravía del interés superior del niño, porque los Defensores de Familia omiten o practican pruebas no idóneas ${ }^{1}$ para determinar las medidas más apropiadas en favor del niño y su familia. En ese sentido, la presunción legal en favor de la familia biológica del niño no logra desvirtuarse, pero se decreta la adopción sin tener los sustentos fácticos para ello, y sin que una homologación por parte del juez sea exigencia para todos los procesos (Sentencia T-844, 2011; Sentencia T-502, 2011; Sentencia T-664, 2012).

Esta falta de claridad en la normatividad deriva también la posibilidad por parte de los Defensores de implementar requisitos extralegales a la hora de determinar, por ejemplo, cuándo el niño debe volver a ser integrado en el seno de su familia (Sentencia T-502, 2011), 
lo que lleva a que no exista seguridad jurídica para la familia cuyo contexto solo debe ser determinante para la separación del niño, cuando es en definitiva un ambiente hostil que impide el desarrollo armónico integral de sus derechos.

Adicionalmente, la discrecionalidad de los Defensores de Familia radica también en la excesiva carga laboral que tienen y en la poca ayuda económica y social que brinda el ICBF. Así lo señaló en entrevista realizada al Defensor de Familia y Presidente de la Agremiación de Defensores de Familia Julián Otálvaro en el año 2016 al Grupo de Investigación:

Las 1.149 defensorías que hay en Colombia tienen actualmente dificultades en recursos humanos y económicos, por lo que no se pueden adelantar los procesos de adopción de muchos niños que están a la espera de ser acogidos por una familia (p. 20).

De ello surge una acumulación de procesos, y de paso, una respuesta tardía a cada uno de ellos (Velásquez de Bernal, 2016), lo que en última instancia perjudica a los niños, que se encuentran en situación de protección, ya que como se ha dicho, el tiempo es su enemigo, porque cada día que pasan sin ser acogidos por una familia, se incrementan las graves consecuencias de la institucionalización, como la sensación de constante abandono o la pérdida de identidad (Sepúlveda, 2015; Strauch-Durán y Valoyes, 2009).

Es un deber del ICBF brindar, en la medida de lo posible, estos recursos (ayuda económica y social) a las Defensorías, para que estas puedan restablecer los derechos de los niños. Incluso, en virtud de ello, muchas no cuentan con un equipo interdisciplinario conformado por trabajador social, nutricionista y psicólogo, indispensable a la hora de evaluar la situación fáctica de los derechos de los niños y de establecer una medida de protección adecuada a sus necesidades. El equipo interdisciplinario es el instrumento que permite garantizar una comprensión efectiva de la situación real del niño, desde otras disciplinas diferentes a la jurídica (Durán, 2008).

De la carencia de equipos interdisciplinarios y de ayudas económicas y sociales suficientes por parte del ICBF, se deriva que estos procesos sean tardíos, generando como consecuencia un retraso en el proceso y así a su vez, la institucionalización de los niños. Esto quiere decir que, a pesar de lo dispuesto en las leyes, donde se establece que el Defensor tiene cuatro o como máximo seis meses (si se le concede un plazo adicional) para declarar un niño en situación de adoptabilidad, la práctica demuestra que no es un plazo respetado, y el proceso administrativo de restablecimiento de derechos se tarda, incluso años, en concluirse (Velásquez de Bernal, 2016).

\section{Derecho del niño a ser escuchado.}

Este derecho se encuentra consagrado en el Artículo 12 de la Convención de los Derechos del Niño y consiste en la oportunidad que se le debe otorgar al niño para dar su opinión en todos aquellos procedimientos judiciales o administrativos donde se ve involucrado su interés superior y la puede expresar de manera directa o a través de un representante (Dirección Nacional de Atención a Grupos en situación de Vulnerabilidad, 2015).

Esa opinión que brinda el niño debe ser libre, carecer de manipulaciones, presiones e influencias y, de esta manera, poder garantizar que lo que dice es realmente lo que quiere. Además de esto, esas opiniones deben ser tenidas en cuenta por quienes toman las decisiones en los procesos que se están adelantando, es decir, por el juez, padres o tutores, y a su vez, estos deben comunicarle al niño las decisiones que se tomaron frente a él (Dirección Nacional de Atención a Grupos en situación de Vulnerabilidad, 2015). 
En principio, es un error creer que la opinión del niño debe ser tomada según la edad y madurez de éste, como lo indican las sentencias T-844 de 2011 y T-129 de 2015, la opinión del niño no solamente se da mediante la expresión verbal, sino también a través de gestos y formas de comportarse, como es el caso de un bebé sonriendo y estirándole los brazos a su padre para ser cargado.

Según lo dicho, se puede afirmar que, en la práctica, tener en cuenta la opinión del niño es una garantía de efectividad y validez del proceso, porque implica que no se incurra en errores fácticos y que con base a las pruebas y a la opinión del niño se pueda tomar la mejor decisión en garantía de sus derechos.

\section{La adopción como medida de protección}

La Corte Constitucional durante los años 2011 a 2016 se ha pronunciado en sus sentencias respecto el concepto y las características de la adopción. Los fallos, en su mayoría, son un complemento de interpretación a la Ley 1098 de 2006; y en otros, se han tomado posturas que pueden cambiar significativamente su alcance.

Por ejemplo, en la sentencia T-844 de 2011, se señala la característica de la irrevocabilidad de la adopción, una vez se hayan agotado los requisitos normativos para su perfeccionamiento. Sin embargo, la Corte alude a que en los casos donde se ha desconocido derechos fundamentales del niño y su familia, sí procede la revocabilidad como algo excepcionalísimo. Al respecto, Jorge Parra Benítez afirma que la irrevocabilidad de la adopción implica que esta no puede dejarse sin efectos por voluntad de quienes intervinieron en su trámite (ParraBenítez, 2008).

Lo anterior, demuestra que el carácter de irrevocabilidad de la adopción no presenta discusión por parte de la generalidad de la jurisprudencia y la doctrina, pues se reconoce la importancia de que una vez se ha restablecido el derecho del niño, no es conveniente revertir todo un proceso ya que se afectaría negativamente su estabilidad emocional, psicológica y social (Sentencia T-844, 2011; Molina, 2002). Así, la irrevocabilidad es un mecanismo de protección del interés superior del niño.

Ahora, en cuanto a la excepción que consagra la Corte para revocar la adopción, el Consejo de Estado ha señalado otra circunstancia que afecta la irrevocabilidad: sucede cuando un colombiano adoptado por extranjeros tiene su residencia fuera de Colombia y conforme a la ley de la nacionalidad de los adoptantes, la adopción podría extinguirse, pero únicamente en lo atinente a los efectos jurídicos que se produzca en el ámbito del ordenamiento extranjero. Es preciso aclarar que esta circunstancia se presenta en casos excepcionalísimos y bajo graves condiciones a nivel internacional, consagradas por la Convención de la Haya relativo a la protección de niños y a la Cooperación en materia de adopción internacional (Consejo de Estado, 1998).

Un segundo hallazgo en la jurisprudencia (Sentencia T-502 de 2011, T-044 de 2014 y C-104 de 2016), señala el carácter de subsidiariedad que tiene la adopción como medida de protección para el restablecimiento de los derechos del niño. La adopción es un mecanismo orientado primordialmente a satisfacer el interés superior de los niños cuando la familia no garantiza las condiciones para la realización y ejercicio de sus derechos (Artículo 22 Código de Infancia y Adolescencia). Sin embargo, debe ser la última medida a la que se acude pues implica una intervención drástica del Estado en la familia, al separar el niño de ella y romper los vínculos biológicos.

En términos de Florencia Burdeos:

Toda política respecto de los niños debe tener como objetivo principal su contención en el núcleo familiar, a través de la implemen- 
tación de planes y programas de prevención, asistencia e inserción social. Se debe aplicar prioritariamente aquellas medidas de protección de derechos que tengan por finalidad la preservación y fortalecimiento de los vínculos familiares con relación a todos los niños; y cuando la amenaza o violación de derechos sea consecuencia de necesidades básicas insatisfechas, carencias o dificultades materiales, laborales o de vivienda; las medidas de protección son los programas dirigidos a brindar ayuda y apoyo incluso económico, con miras al mantenimiento y fortalecimiento de los vínculos familiares (Burdeos, 2008, p. 25).

De acuerdo a la jurisprudencia, el Código de la Infancia y la Adolescencia, la Convención sobre los Derechos del Niño y lo establecido por el Instituto Colombiano de Bienestar Familiar (ICBF) en sus Lineamientos Técnicos Administrativos, en ningún caso la condición económica de la familia puede dar lugar a la separación o adopción. El Estado en su deber de corresponsabilidad en la atención y cuidado de los niños (Artículo 10 Ley 1098 de 2006), debe garantizar las condiciones necesarias para brindar una protección integral, que se materializa a través del conjunto de políticas, planes, programas y acciones que se ejecuten en los ámbitos nacional, departamental, distrital y municipal con la correspondiente asignación de recursos financieros, físicos y humanos (Artículo 7, Código de Infancia y Adolescencia).

En ese sentido, la Corte en sus sentencias ha ordenado al ICBF a cumplir con lo anterior, estableciendo pautas y mandatos para que no solo sea restablecido el derecho del niño, sino que dicha protección pueda permanecer en el tiempo y continuando en un proceso de acompañamiento y apoyo a la familia, según lo necesite cada caso particular.

El tercer hallazgo se encuentra en la sentencia T-119 de 2016 la cual prohíbe las adopciones determinadas - exceptuando las adopciones de familiares-, es decir, elegir a un niño o adolescente en especial, porque dejaría de ser una medida de protección y se convertiría en una medida discriminatoria y violatoria del principio de igualdad.

La Corte afirma que la adopción no pretende que quienes carecen de un hijo puedan llegar a tenerlo, sino que el niño que no tiene padres pueda llegar a ser parte de una familia (Sentencia C-683 de 2015). Debe tratarse como un derecho prevalente del niño a tener una familia, al amor y a la protección y no solo como un derecho de las parejas a tener hijos (Vélez, 2011).

Sin embargo, la Corte hace una precisión y señala que es posible la adopción de un niño o adolescente determinado, bajo la excepción de inconstitucionalidad, cuando existen vínculos de afecto y representaciones familiares de los niños hacia los posibles adoptantes, de tal manera que, si no se da la adopción entre ellos, se incidiría negativamente sobre su estado emocional (Sentencia T-119 de 2016).

El último hallazgo consiste en que la Corte Constitucional, en el año 2015, en la sentencia C-071, se pronunció sobre la constitucionalidad de la norma que establece la adopción para parejas heterosexuales, declarando su exequibilidad y no permitiendo la adopción por parte de parejas del mismo sexo, haciendo una salvedad y única excepción, en el caso de la adopción de los hijos biológicos de la pareja homosexual. Sin embargo, la sentencia C-683 del mismo año, le otorga un nuevo sentido a la expresión "cónyuge o compañero permanente" al incluir a las parejas del mismo sexo.

\section{Presunción de familia biológica}

Ahora bien, respecto al concepto de familia, la Corte Constitucional ha estimado una presunción legal a favor de las distintas formas de organización familiar, debido a que la familia se considera el entorno propicio para garantizar el desarrollo armónico e integral del niño. No obstante, las sentencias señalan ciertos pa- 
rámetros para determinar en qué situaciones concretas se justifica apartar el niño del núcleo familiar a través de medidas de intervención estatal en pro de velar por su interés superior.

En consecuencia, la Corte Constitucional basándose en los artículos 5, 15, 28, 42 y 44 de la Constitución Política, para garantizar la protección de los derechos del niño y los derechos de su familia, estableció una presunción legal en favor de la familia de origen, toda vez que considera que ella es el entorno adecuado para brindarle al niño toda la atención, la protección, el afecto, la crianza y la educación que necesita, es decir, la familia es el lugar para garantizarle al niño un desarrollo óptimo, porque allí se presentan estrechos vínculos de afecto y confianza, y a su vez, relaciones equilibradas y armónicas entre los padres y los hijos. Por lo anterior, se prefiere conservar el vínculo paterno-filial existente entre el niño con la familia de origen, que romperlo, para generar un vínculo nuevo con otra familia, que puede desatar procesos "traumáticos" para los niños, que en la mayoría de los casos terminan incidiendo en el comportamiento de los mismos (Sentencia T-211 de 2014).

Por su parte, se encontró que la doctrina trae una aproximación genérica a la presunción legal que trae la Corte Constitucional, toda vez que, como la familia se encuentra en una condición favorable para brindarle al niño todos los beneficios y protección que éste necesita, se deben adoptar las medidas necesarias para que el niño no sea separado de su familia, y en caso de ser así por algún motivo, pueda ser reintegrado a la misma, de conformidad con lo previsto en los artículos 23 y 24 del Código de Infancia y Adolescencia. Como complemento de lo anterior, existe la posibilidad por parte de la familia para acceder a subsidios y beneficios estatales para la conservación y el restablecimiento de los derechos del niño (Medina-Pabón, 2014).

Sin embargo la presunción legal en favor de la familia de origen puede ser desvirtuada, en aquellos casos en los que se evidencien argumentos objetivos que cuestionen el bienestar del niño en ese entorno familiar, así como la existencia de peligros concretos en aquella para su desarrollo. Es en este punto, donde la Corte enfatiza que la intervención estatal procede únicamente cuando la familia no puede asumir plenamente la protección y la asistencia del niño (Sentencia T-502 de 2011).

En el mismo sentido la Corte expresa que, en aras de la conservación del interés superior del niño, el Estado tiene la facultad de limitar los derechos que poseen los padres sobre sus hijos, cuando existan: i) claros riesgos para la vida, la integridad o la salud del niño o la niña; ii) antecedentes de abuso físico, sexual o psicológico en la familia; o iii) las circunstancias frente a las cuales el Artículo 44 de la Constitución Política ordena protección: abandono, violencia física o moral, secuestro, venta, abuso sexual, explotación laboral o económica y trabajos riesgosos (Sentencia T-044, 2014; Sentencia T-212, 2014).

De presentarse uno de los anteriores supuestos, el Estado tiene la obligación de intervenir en pro de restablecerle los derechos al niño, restaurándole su dignidad e integridad como sujeto derechos. Para esto la autoridad competente debe tomar una medida, verificando: i) su salud física y psicológica; (ii) su estado de nutrición y vacunación; (iii) su inscripción en el registro civil de nacimiento; (iv) la ubicación de su familia de origen; (v) el estudio de su entorno familiar e identificación tanto de elementos protectores como de riesgo para la vigencia de sus derechos; (vi) su afiliación al sistema de seguridad social; y (vii) su vinculación a entes educativos. Una vez determinada la situación real en la que se encuentra el niño, la autoridad competente deberá adoptar las medidas de restablecimiento (provisionales o definitivas) más convenientes, y son: (i) amonestación; (ii) retiro inmediato de los niños de la actividad que amenace o vulnere sus derechos o de las actividades ilícitas en que se pueda encontrar, y ubicación 
en un programa de atención especializada; (iii) ubicación inmediata en medio familiar, ya sea con su familia extensa, en hogar de paso cuando no aparecen parientes o personas que puedan cuidar del niño, o en hogar sustituto, es decir en una familia que se comprometa a brindarle el cuidado y atención necesaria en sustitución a sus parientes de origen; (iv) ubicación en centros de emergencia para los casos en los que no procede ubicación en los hogares de paso; (v) adopción; y (vi) las consagradas en otras disposiciones legales, o cualquier otra que garantice la protección integral de los niños (Sentencia T-044 de 2014; Sentencia T-212 de 2014).

En estas medidas de restablecimiento de derechos, podemos observar la presunción legal a favor de la familia de origen, toda vez que de las seis medidas mencionadas, la única que está destinada a romper el vínculo familiar es la adopción, mientras las otras buscan la reubicación del niño donde se encontraba antes. Incluso, para la aplicación de la adopción, se tiene una garantía procesal adicional para la familia de origen, el control de homologación judicial, donde el juez revisa el procedimiento administrativo mediante el cual se decidió declarar al niño en situación de adoptabilidad, a partir de la defensa que realiza familia de origen para conservar el vínculo con el niño.

En consecuencia, si el juez decide homologar, esto es, validar la Resolución de Declaratoria de Adoptabilidad, que conlleva la pérdida de la patria potestad, la cual debe ser inscrita en el libro de varios de la notaría o en la oficina de Registro del Estado Civil e ingresa al niño al programa de adopciones del ICBF. Por el contrario, en caso de negarse la homologación, el Defensor de Familia también deberá expedir una Resolución indicando lo resuelto por el Juez y debe proceder a subsanar las inconsistencias manifestadas en el fallo o, en caso de no ser subsanables, aplicar unas medidas de restablecimiento diferentes a la adopción.
Por otra parte, la Corte ha señalado que al declarar un niño en adoptabilidad, el argumento económico no es relevante, porque constituiría un restricción desproporcionada del derecho del niño a tener un familia y desencadenaría en un trato discriminatorio de aquellas que no cuenta con recursos económicos, pero que sí podría cumplir con los deberes que le señala la ley respecto a sus hijos (Sentencia T-502 de 2011; Sentencia T-212 de 2014).

Debido a lo anterior, la Corte ha resaltado en sus sentencias que las autoridades nacionales, departamentales y locales se encuentran obligadas por la Constitución Política a diseñar e implementar políticas públicas eficaces que velen por la conservación del núcleo familiar, medidas que permitan un equilibrio entre la satisfacción de las necesidades económicas de las familias y la atención y cuidados especiales que merecen los niños. Lo anterior teniendo en cuenta programas sociales dirigidos a brindarles a las familias opciones para que los niños permanezcan en un ambiente familiar sano y seguro, mientras que sus padres cumplen con sus deberes con ellos (Sentencia T-044, 2014).

\section{Conclusiones}

Los problemas en el proceso administrativo de restablecimiento de derechos generan un gran impacto en el proceso de adopción produciendo un retardo injustificado. Esto se evidencia en los casos de adopciones que son rechazadas por los Jueces de Familia por falta de sustentos fácticos en la práctica de pruebas y omisión de escuchar al niño que surgen de la discrecionalidad de la que se faculta al Defensor de Familia y de la carencia de pautas claras de acción. Ahora, lo más grave de todo, es la inseguridad jurídica para la familia y para el niño, ya que el proceso de adopción en lugar de ser un espacio de restablecimiento de derechos, se convierte en un espacio de vulneración, amenaza o inobservancia de éstos. 
En el proceso administrativo de restablecimiento de derechos donde el Defensor de Familia debe decidir la medida de protección, sea la adoptabilidad de un niño o la ubicación en familia de origen o extensa, prevalece el rigorismo legislativo y jurisprudencial sobre los derechos de los niños, pues por temor a sanciones por no efectuar la búsqueda imposible hasta el sexto grado de consanguinidad en línea recta o colateral, no emite sus actos administrativos y los niños quedan en una indeterminación de su situación jurídica, lo que los convierte en hijos del Estado.

Las sentencias de la Corte Constitucional evidencian que éste organismo lo que hace es repetir y recordar lo que ya se encuentra estipulado en Convenciones Internacionales, Código de la Infancia y la Adolescencia y en los lineamientos técnicos del ICBF en razón del interés superior del niño y la protección a su derecho de tener una familia y a no ser separado de ella, al margen de posturas tan exegéticas como la del ICBF al malinterpretar lo dicho por la Corte en la Sentencia T-844 de 2011.

Conforme al análisis realizado en las sentencias de la Corte, pone de manifiesto que se han introducido avances y logros en materia de adopción; sin embargo, aún falta precisión y efectividad a la hora de aplicar la normatividad y los principios señalados en la Convención de los Derechos de los Niños.

Igualmente se resalta la noción de familia extensa la cual debe hoy analizarse desde los vínculos de solidaridad y cooperación forjados a lo largo de la vida que en momentos de necesidad se manifiestan a través del cariño y el cuidado para la protección de los derechos de los niños.

\section{Referencias}

Burdeos, F. (2008). La adopción como medida de protección. Anales de la Facultad de Ciencias Jurídicas y Sociales, 5(38), p. 122.

Cuartas Rodríguez, P. (17 de Febrero de 2015). La eterna espera de los niños huérfanos. El Espectador. Recuperado de: https://www.elespectador.com/noticias/ nacional/eterna-espera-de-los-ninoshuerfanos-articulo-544704

Dirección Nacional de Atención a Grupos en situación de Vulnerabilidad. (05 de agosto de 2015). Derecho del niño y la niña a ser escuchado. Recuperado de: http://www.jus.gob.ar/media/2954702/ ni_ez_cuadernillo_05082015.pdf

Duque-Camacho, A. P., y Ramirez-Torres, L. M. (2010). La adopción una medida de protección, garantía y restablecimiento de derechos de las niñas y los niños en Colombia. Bogotá, Colombia.

Durán, E. (2008). Situación de los derechos de la infancia de niños y niñas que han perdido el cuidado de sus padres o están en riesgo de perderlo. Bogotá: Aldeas Infantiles SOS.

Durán Strauch, E., y Valoyes, E. (2009). Perfil de los niños, niñas y adolescentes sin cuidado parental en Colombia. Revista Latinoamericana de Ciencias Sociales, Niñez y Juventud, 7(2), 761-783.

Estrada Vélez, S. (2011). Familia, matrimonio y adopción: algunas reflexiones en defensa del derecho de las parejas del mismo sexo a constituir familia y de los menores a tenerla. Revista de Derecho, (36), 126-159.

Fernández Molina, M. (2002). Descripción del proceso de adaptación infantil en adopciones especiales. Dificultades y cambios observados por los padres adoptivos. Anales de Psicología, 18(1), 151-168. 
Instituto Colombiano de Bienestar Familiar [ICBF]. (10 de mayo de 2012). Concepto 69. Colombia.

Instituto Colombiano de Bienestar Familiar - [ICBF]. (15 de enero de 2016). Líneamiento administrativo de ruta de derechos de niños, niñas y adolescentes con sus derechos inobservados, amenazados o vulnerados. Colombia: Autor.

Instituto Colombiano de Bienestar Familiar[ICBF]. (2016). Guía para la preparación de niños, niñas y adolescentes para la adopción. Bogotá.

Ley 1098 de 2006. Por la cual se expide el Código de la Infancia y la Adolescencia. Diario Oficial No. 46.446. Congreso de la República de Colombia, noviembre de 2006.

Medina-Pabón (2014). Derecho Civil: Derecho de Familia (4 ed.). Bogotá, D.C.: Editorial Universidad del Rosario.

Monroy-Cabra, M. G. (2012). Derecho de Familia, Infancia y Adolescencia. (14 $\left.{ }^{\mathrm{a}} \mathrm{ed}\right)$. Bogotá, D.C.: Librería Ediciones del Profesional Ltda.

Parra-Benítez, J. (2008) Derecho de Familia. Ed. Temis. Bogotá.

Ramírez Vélez, V. E., Aranceta Ruiz, M., y Montoya Daza, F. (2015). Contradicciones en el proceso de restablecimiento de derechos de los niños, las niñas y los adolescentes en colombia. Medellín: Universidad de Medellín.

Sala de Consulta y Servicio Civil, 1101-0306.000-2014-00175-00 (22224). Consejo de Estado 2014.

Salcedo, L. M. (2015). Alcance de la Sentencia T-844 de 2011 en la declaratoria de adoptabilidad en favor de la familia extensa [Trabajo de grado]. Bogotá: Universidad de los Andes.
Sentencia C-370 de 2006. Demanda de Inconstitucionalidad. M.P. Humberto Antonio Sierra Porto. Corte Constitucional.

Sentencia C-456 de 1997. Demanda de inconstitucionalidad contra el artículo 127 del decreto 100 de 1980 "Por medio del cual se expide el Código Penal". M.P. Jorge Arango Mejía y Eduardo Cifuentes Muñoz. Corte Constitucional.

Sentencia C-577 de 2014. Demanda de inconstitucionalidad contra el artículo $1^{\circ}$ (parcial) y el artículo $3^{\circ}$ del Acto Legislativo 1 de 2012 "Por medio del cual se establecen instrumentos jurídicos de justicia transicional en el marco del artículo 22 de la Constitución Política y se dictan otras disposiciones". M. P. Martha Victoria Sáchica Méndez. Corte Constitucional.

Sentencia C-579 de 2013. Demanda de inconstitucionalidad contra el artículo $1^{\circ}$ del Acto Legislativo 01 de 2012 (parcial). M.P. Jorge Ignacio Pretelt Chaljub. Corte Constitucional.

Sentencia C-695 de 2002. Demanda de inconstitucionalidad contra el artículo 13 de la Ley 733 de 2002. M. P. Jaime Córdoba Triviño. Corte Constitucional.

Sentencia C-928 de 2005. Demanda de inconstitucionalidad contra el Art. 19 (parcial) de la Ley 782 de 2002. M. P. Jaime Araujo Renteria. Corte Constitucional.

Sentencia SU-062 de 2010. Acción de tutela instaurada por Javier de Jesús Taborda Quintero contra ING Pensiones y Cesantías y el Instituto de Seguros Sociales. M.P. Humberto Antonio Sierra Porto. Corte Constitucional.

Sentencia T-502 de 2011. Acción de Tutela instaurada por Helena y Diego, contra el Instituto Colombiano de Bienestar Familiar. M. P. Jorge Ignacio Pretelt Chaljub. Corte Constitucional. 
Sentencia T-129 de 2015. Acción de tutela instaurada por Adolfo, contra el Instituto Colombiano de Bienestar Familiar. M. P. Martha Victoria Sáchica Méndez. Corte Constitucional.

Sentencia T-502 de 2011. Acción de Tutela instaurada por Helena y Diego, contra el Instituto Colombiano de Bienestar Familiar. Jorge Ignacio Pretelt Chaljub. Corte Constitucional.

Sepúlveda, G. P. (25 de octubre de 2015). Los niños sin fotos. La tercera. Recuperado de: http://www.latercera.com/noticia/ tendencias/2015/10/659-652891-9-losninos-sin-fotos.shtml
Velásquez de Bernal, O. M. (14 de junio de 2016). Las paradojas de la adopción en Colombia. El Tiempo. Recuperado de: https://www.eltiempo.com/archivo/ documento/CMS-16620416

Notas

${ }^{1}$ La práctica de pruebas no idóneas o la ausencia de estas origina lo que conocemos como defecto fáctico, que suele inducir en error al juez encargado del proceso. Las fallas reales se evidencian, por ejemplo, en contradicción en la práctica de pruebas, omisión de declaraciones de la familia de origen e incluso, una inadecuada reco lección de las mismas. 